\title{
Zero-inflated binomial regressions for modelling low prevalence of pathogens in chicken meat as affected by sampling site
}

\author{
Marta Hernández ${ }^{\mathrm{a}, \mathrm{b}}$, David Rodríguez-Lázaro ${ }^{\mathrm{b}}$, Antonio Valero ${ }^{\mathrm{c}}$, Vasco Cadavez $^{\mathrm{d}}$, \\ Ursula Gonzales-Barron ${ }^{\mathrm{d}, *}$ \\ a Laboratorio de Biología Molecular y Microbiología, Instituto Tecnológico Agrario de Castilla y León (ITACyL), Valladolid, Spain \\ ${ }^{\mathrm{b}}$ Department of Biotechnology and Food Science, Faculty of Sciences, University of Burgos, Burgos, Spain \\ ${ }^{\mathrm{c}}$ Department of Food Science and Technology, University of Cordoba, Campus de Rabanales, Edificio Darwin, Córdoba 14014, Spain \\ ${ }^{\mathrm{d}}$ CIMO Mountain Research Centre, School of Agriculture, Polytechnic Institute of Bragança, Bragança 5300-253, Portugal
}

\section{A R T I C L E I N F O}

\section{Keywords:}

Salmonella

Listeria monocytogenes

Staphylococcus aureus

Poultry

Sampling

\begin{abstract}
A B S T R A C T
Contamination of raw poultry meat with foodborne pathogens could occur because of improper handling at primary production and slaughterhouse levels. Low microbial prevalence data often consists of a high amount of non-detections (zero positives), so a flexible framework is required to characterise the underlying microbial distribution and conduct reliable inferential statistics. Thus, the objective of this work was to evaluate the performance of zero-inflated binomial (ZIB) regression models to describe the effects of sampling site (carcass, thigh, breast, wings) on the measured incidences of Salmonella, Listeria monocytogenes and Staphylococcus aureus on chicken meat. For each pathogen, four regression models based on the zero-inflated binomial ZIB $\left(p, w_{0}\right)$ distribution were fitted to the presence/absence data with sampling site as covariate and random-effects due to sampling occasion either in the binomial probability $(p)$ or in the extra-proportion of non-detections $\left(w_{o}\right)$. For the three pathogens, the sampling site exerted a greater effect on $w_{0}$ than on $p$ itself, with breast bearing the lowest prevalence estimates of Salmonella spp. (mean: 0.88\%; 95\% CI: 0.02-1.95\%) and S. aureus (mean 1.48\%; 95\% CI: 0.01-4.00\%). The fitting capacity of the models was further improved when random effects due to sampling occasion were placed in $w_{O}$ (deviances decreased from 146.7-156.7 to 140.2-140.6). This would imply that, theoretically, the variability in pathogens' occurrence from batch to batch mainly arises from the variability in non-contaminated zones. At any sampling site, the mean prevalence was estimated as 1.35 (95\% CI: 0.15 - 2.70) for Salmonella, 2.11 (95\% CI: 0.04 - 5.63) for L. monocytogenes and 2.36 (95\% CI: $0.04-5.12$ ) for S. aureus. Sampling performance analysis showed that wings were mostly suitable to detect Salmonella and $S$. aureus with higher probability ( 0.016 and 0.035 respectively), while for L. monocytogenes, sampling of thigh could be more effective (0.032).
\end{abstract}

\section{Introduction}

Consumption of poultry meat remains popular worldwide due to its convenience, availability and balanced chemical composition in comparison with other types of meats (Farrell, 2013). However, microbial contamination of raw poultry meat could occur as a consequence of improper handling at primary production and slaughterhouse levels (Pasquali et al., 2017). Enteric pathogens can be present at farm level (i.e. cross-contamination between flocks, animal breeding, faecal contamination etc.) and further transmitted to the poultry chain during slaughterhouse operations, distribution, retail marketing, preparation and consumption (Dookeran et al., 2012; Schäfer et al., 2017; Wang et al., 2018). Management of hazards transmitted to humans by consumption of chicken meat is therefore of major health and economic significance.

Regarding the most implicated biological hazards, Salmonella presented the highest levels of non-compliance in poultry meat intended to be eaten cooked with $6.45 \%$ of single samples and $6.0 \%$ of batches in 2016 (EFSA, 2017). Poultry meat has also been implicated as a vehicle in the transmission of L. monocytogenes (Carpentier and Cerf, 2011; Alonso-Hernando et al., 2012) given its ability to grow at refrigeration temperatures in raw chicken meat (Sahu et al., 2017). The presence of L. monocytogenes has been reported in chicken breast $(8.64 \%)$ and chicken thigh $(44.19 \%)$ in poultry slaughter plants (Schäfer et al., 2017). Similar levels were found by Elmali et al. (2015) in broiler wing meat samples $(45 \%)$ highlighting seasonal differences in prevalence

\footnotetext{
* Corresponding author.

E-mail address: ubarron@ipb.pt (U. Gonzales-Barron).
} 


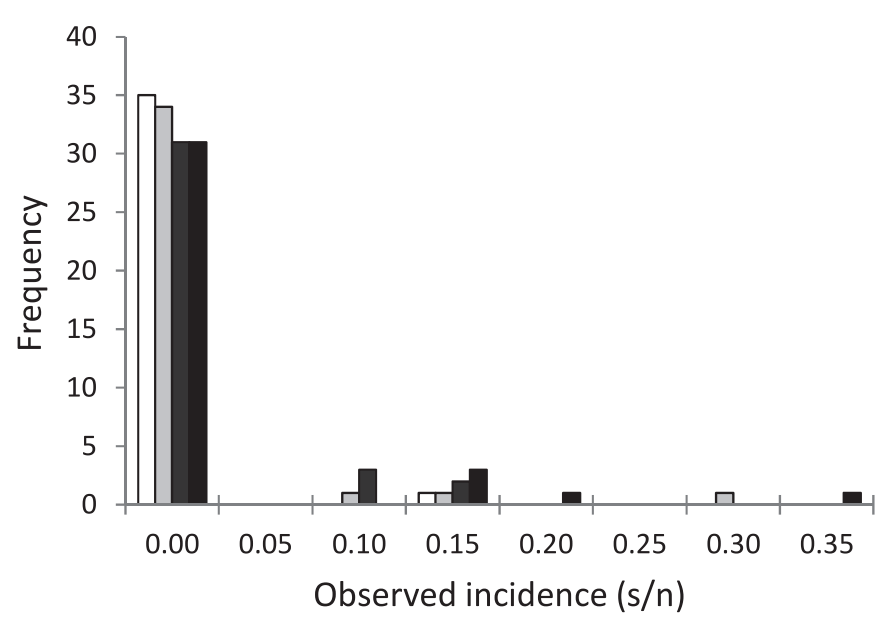

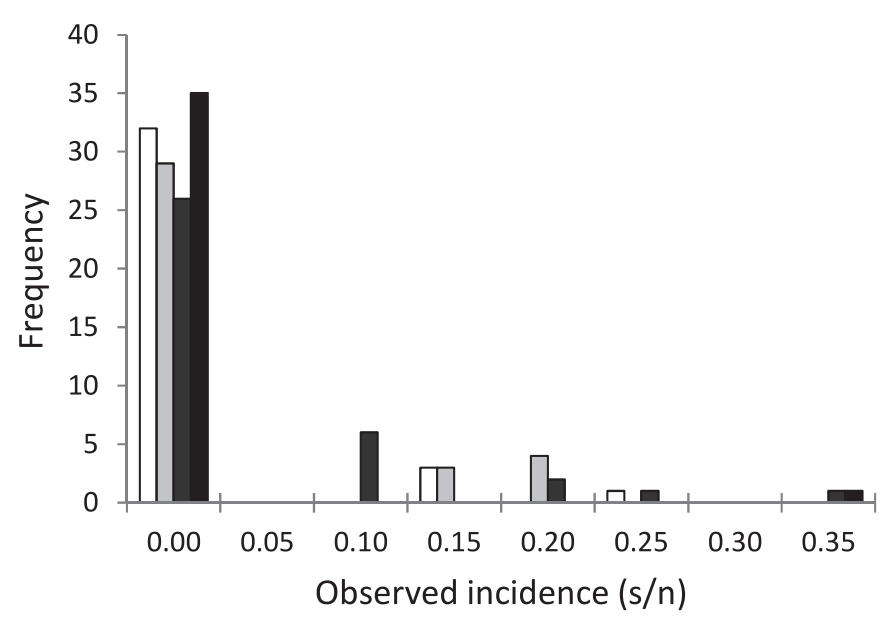

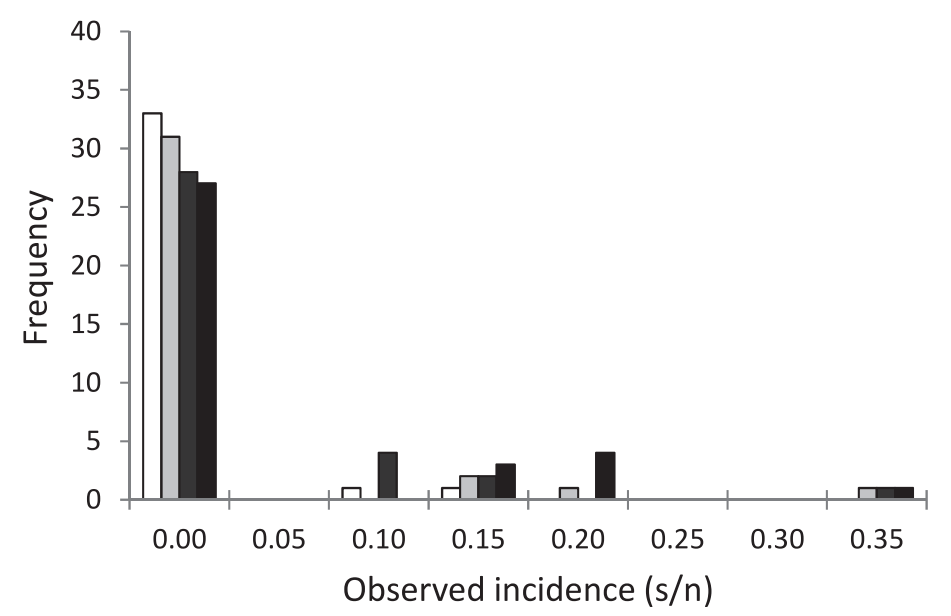

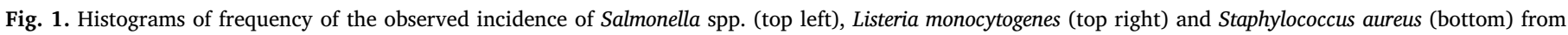
sampling chicken breast (white), carcass (light grey), thigh (dark grey) and wings (black bars) at a production facility.

levels. Lastly, Staphylococcus aureus and their methicillin-resistant strains (MRSA) are also associated to contaminated raw chicken products because of direct exposure during breeding, slaughtering, production, storage and distribution phases (Oniciuc et al., 2017; Wang et al., 2018). Antibiotic resistant $S$. aureus strains can be found in poultry meat $(18.18 \%)$ showing some of them multidrug resistance (Akbar and Anal, 2013).

An adequate statistical characterization of the distribution of microorganisms in batches of food are helpful to risk assessors and food safety managers, both to set and evaluate the performance of safety targets so that the number of contaminated batches before consumption is reduced (Reich et al., 2018). However, when attempting to describe the frequencies of most food-borne pathogens, the statistical distributions should be able to account for the data over-dispersion (variance $>$ mean) often produced by a high proportion of negative results. In the case of microbial counts data, previous research has demonstrated that heterogeneous Poisson distributions and their zero-inflated variants are far more suitable to characterise low bacterial concentrations in foods than the simple Poisson or lognormal distributions (Gonzales-Barron et al., 2014; Gonzales-Barron and Butler, 2011a, 2011b). As observed with counts data, prevalence data of pathogens can also comprise a high number of non-detections; that is, no positive samples out of a total sample size. If such over-dispersed prevalence data were mistakenly represented by a single binomial probability (from a binomial distribution), the frequencies of non-detections would be underestimated, which will in turn produce biased risk assessment estimates. Ways of tackling over-dispersed prevalence data are by producing variability in the binomial probability (i.e., for instance by a beta-binomial distribution), by inflating the proportion of non-detections (i.e., a zero-inflated binomial distribution), or both. Whichever the strategy, a closer statistical depiction of pathogens of low occurrence in foods will not only lead to more accurate risk assessment models and sampling strategies but will also serve as a basis for the conduction of appropriate inferential statistics beyond the common assumption of a binomial or normal data distribution (GonzalesBarron et al., 2014). Thus, the objective of this work was to introduce a modeling framework to conduct inferential statistics on microbial prevalence data that fail to approximate to a binomial distribution due to the high proportion of non-detections. As an illustration, we will evaluate the performance of zero-inflated binomial regressions models to assess the effects of sampling site (carcass, thigh, breast, wings) on the measured incidences of Salmonella spp., L. monocytogenes and S. aureus on chicken meat. For this aim, a number of fixed- and random-effects models were evaluated and compared in terms of goodness-of-fit and predictability. Finally, the appropriateness of the zero-inflated binomial estimates in the design and assessment of the performance of sampling plans was discussed. 


\section{Material and methods}

\subsection{Sampling of chicken carcasses and microbiological analyses}

Chicken samples from carcasses, collected before jointing, and thigh, breast and wings, collected after jointing, were taken monthly from January 2014 until December 2016 from a Spanish slaughterhouse. In each of the 36 sampling visits, six to twenty chickens were sampled and they were assumed to belong to the same production batch (i.e., 36 batches). According to the month of the survey, year's season (i.e., spring, summer, autumn or winter) was another variable annotated in the data set.

A portion of each sample ( $25 \mathrm{~g}$ ) was obtained after processing (before packaging) by excising the external surface with a sterile scalpel and transferring the material into a sterile sample bag. Samples were transported at refrigeration conditions to the laboratory for microbial analysis. Analyses were carried following ISO methods for each pathogen (ISO 6579 for Salmonella spp. (ISO, 2002), ISO 11290-1 (ISO, 2017) and -2 (ISO, 2004) for L. monocytogenes and ISO 6888 for $S$. aureus (ISO, 1999)).

In most of the sampling visits or batches ( $\sim 86 \%)$, Salmonella, $L$. monocytogenes or $S$. aureus were not detected in any of the samples. At an individual-sample basis, bringing together the four chicken sites, these pathogens were detected in 16 out of 1,330 samples, 31 out of 1,326 samples and 27 out of 1277 samples, respectively. Batch-level observed microbial incidences are shown by sampling site and pathogen in Fig. 1, whereby the total sample size $\mathrm{n}$ taken from a batch, per visit, varied from 6 to 20 ( $\sim 10$ samples on average).

\subsection{The zero-inflated binomial model}

In its simplest form, the binomial distribution models the number of successes $s$ (i.e., samples that tested positive for a pathogen) in a sequence of $n$ independent experiments (i.e., total sample size drawn from a bigger population), each of which yields positive with a probability $p$. If such probability is assumed invariable in time, the probability of obtaining $s$ positive samples from a sample size $n$ at every sampling visit $i$ is given by the probability mass function:

$\operatorname{Pr}\left(s_{i}\right)=\left(\begin{array}{c}n_{i} \\ s_{i}\end{array}\right) p^{s_{i}}(1-p)^{n_{i}-s_{i}}$

In a binomial regression model, the binomial probability $p$ is allowed to change $\left(p_{i}\right)$ as a function of a vector of covariates $X$, where $\beta$ is a parameter vector. The covariate effects can be linked to $p$ through a logit transformation.

$\operatorname{logit}\left(p_{i}\right)=\ln \left(\frac{p_{i}}{1-p_{i}}\right)=\beta_{0}+\beta_{k} X$

The prevalence data of pathogens is normally characterised by a high percentage of non-detections, which may not be accounted for by the restricted variance of the binomial distribution (variance $<$ mean). To model this excess of non-detections, a mixture of two distributions was considered: a degenerate distribution for the non-detections and a standard binomial distribution. This type of distribution is called zeroinflated binomial (ZIB), and it assumes that the individual incidence can originate from two stochastic processes: one process will always have a count of zero (i.e., none of the samples testing positive; $s=0$ ), while the other will follow a binomial distribution which is also responsible for generating non-detections. The probability mass function is given by,

$\operatorname{Pr}\left(s_{i}\right)=\begin{array}{cc}w_{0}+\left(1-w_{0}\right) g(0) & \text { for } s_{i}=0 \\ \left(1-w_{0}\right) g\left(s_{i}\right) & \text { for } s_{i} \geq 1\end{array}$

where $g$ is the probability mass function corresponding to the binomial distribution. Notice from the above equation, that a non-detection $(s=0)$ can arise from the fixed-zero group with a probability $w_{0}$ or from the binomial distribution $g$ with a probability $1-w_{0}$. Thus, $w_{0}$ can be regarded as the extra proportion of non-detections arising from sampling sites that are "free of contamination", assuming that a negative result is a "true" negative. The membership of the fixed-zero group is estimated by a probability $w_{0}$, which is calculated by a logit transformation with $\gamma_{o}$ as intercept.

$\operatorname{logit}\left(w_{0}\right)=\ln \left(\frac{w_{0}}{1-w_{0}}\right)=\gamma_{0}$

Substituting $g$ in Eq. (1) produces the probability mass function of the ZIB distribution,

$\operatorname{Pr}\left(s_{i}\right)=\begin{array}{cc}w_{0}+\left(1-w_{0}\right)\left(1-p^{n_{i}}\right) & \text { for } s_{i}=0 \\ \left(1-w_{0}\right)\left(\begin{array}{c}n_{i} \\ s_{i}\end{array}\right) p^{s_{i}(1-p)^{n_{i}-s_{i}}} & \text { for } s_{i} \geq 1\end{array}$

The log-likelihood function of the ZIB distribution is then computed as,

$L L_{Z I B}=\Sigma\left|\begin{array}{l}I\left(s_{i}=0\right) \ln \left[w_{0}+\left(1-w_{0}\right)\left(1-p^{n_{i}}\right)\right]+ \\ I\left(s_{i} \geq 1\right)\left[\ln \left(1-w_{0}\right)+\ln \left\{\Gamma\left(n_{i}+1\right)\right\}-\ln \left\{\Gamma\left(s_{i}+1\right)\right\}-\right. \\ \ln \left\{\Gamma\left(n_{i}+s_{i}+1\right)\right\}+s_{i} \ln (p)+\left(n_{i}-s_{i}\right) \ln (1-p)\end{array}\right|$

\subsection{Zero-inflated binomial (ZIB) regression models}

Although it is not technically incorrect to fit four separate ZIB distributions of a specific pathogen to the data from each of the four sampling sites; in order to meet the objective of this study - which is to illustrate how to conduct inferential statistics on over-dispersed microbial prevalence data - a regression framework with sampling site as covariate was instead employed. In such a framework, as the effect of sampling site is to be tested, the results from the four different sampling sites must be combined into a single regression model for a given pathogen. A number of ZIB regressions were preliminarily evaluated, yet the most parsimonious and interpretable are presented, as follows:

\subsubsection{Model 1: ZIB with fixed-effects in the binomial probability $p$}

Suppose that all products sampled from the same "batch" originate from the same flock and, therefore, are either contaminated or not; while chicken products (i.e., carcass, breast, thigh and wings) in a contaminated batch have different inherent probabilities of being positive. Thus, mathematically, this model assumes that the sampling site does not have any effect on the extra proportion of zeros $w_{O}$ but affects the binomial probability $p$. Some sites can be thought of being more frequently contaminated than others. As no variability due to annual season or batch is allowed in this model, the fixed-effects ZIB regression is fitted as,

$$
\begin{aligned}
& \operatorname{logit}(p)=\ln \left(\frac{p}{1-p}\right)=\beta_{0}+\beta_{k} S \\
& \operatorname{logit}\left(w_{0}\right)=\ln \left(\frac{w_{0}}{1-w_{0}}\right)=\gamma_{0}
\end{aligned}
$$

where the covariate $S$ is a categorical variable denoting sampling site, with $k=4$ classes: wings, breast, carcass and thigh. The effect $\beta_{k}$ of each sampling site $k$ is calculated as a fixed-effects term; this is, as an average effect of all batches.

\subsubsection{Model 2: ZIB with fixed-effects in the extra-proportion of non- detections $w_{O}$}

Now, suppose that chicken products are handled differently at slaughter such that decontamination is different for each product, but the prevalence across contaminated batches of the products is similar. Then, mathematically, this model assumes that the underlying binomial probability $p$ (i.e., prevalence of pathogens) is common for all the 
sampled batches of chicken. However, the extra proportion of non-detections $w_{0}$, which ultimately affects our observed mean prevalence from the batches, depends upon the sampling site. Some chicken sites can be thought of being more frequently "free-of-contamination" (i.e., higher proportion of non-detections $w_{0}$ ) than others. The fixed-effects ZIB regression is fitted as,

$$
\begin{aligned}
\operatorname{logit}(p) & =\ln \left(\frac{p}{1-p}\right)=\beta_{0} \\
\operatorname{logit}\left(w_{0}\right) & =\ln \left(\frac{w_{0}}{1-w_{0}}\right)=\gamma_{0}+\gamma_{k} S
\end{aligned}
$$

The effect $\gamma_{k}$ of each sampling site $k$ is calculated as a fixed-effects term; this is, as an average effect of all batches.

\subsubsection{Model 3: model 2 with random-effects in the extra-proportion of non- detections $w_{0}$}

This model also estimates a common binomial probability $p$ for all the batches. However, it does not only allow for a different extra proportion of non-detections according to sampling site but also extracts the variability due to sampling occasion. Thus, the model becomes

$$
\begin{aligned}
\operatorname{logit}(p) & =\ln \left(\frac{p}{1-p}\right)=\beta_{0} \\
\operatorname{logit}\left(w_{0}\right) & =\ln \left(\frac{w_{0}}{1-w_{0}}\right)=\gamma_{0}+\gamma_{k} S+u_{j}
\end{aligned}
$$

where the random effect $u_{j}$ models the shift in the intercept $\gamma_{o}$, assumed to be a realisation from a normal distribution with mean zero and standard deviation $\sigma_{u}$. The subject of variation of these random effects is sampling occasion $j$, which, depending on the pathogen under study, could be either batch or year's season. The selection of the subject of variation was based on model's stability.

\subsubsection{Model 4: model 2 with random-effects in the binomial probability $p$}

In this regression model, the binomial probability $p$ is no longer fixed but can take different values $u_{j}$ depending on the sampling occasion $j$. The model then becomes,

$$
\begin{gathered}
\operatorname{logit}(p)=\ln \left(\frac{p}{1-p}\right)=\beta_{0}+u_{j} \\
\operatorname{logit}\left(w_{0}\right)=\ln \left(\frac{w_{0}}{1-w_{0}}\right)=\gamma_{0}+\gamma_{k} S
\end{gathered}
$$

where, again, the subject of variation of the random effects $u_{j}$ is sampling occasion, represented by batch or season - whichever leads to a more stable model. The random effects $u_{j}$ follow a normal distribution with mean zero and standard deviation $\sigma_{u}$.

\subsection{Model fitting}

The four models were fitted to each of the three microbial data sets using the Markov chain Monte Carlo (MCMC) technique via WINBUGS 1.4.3 (MRC Biostatistics Unit Cambridge). The MCMC technique was chosen because it makes the adjustment of complex models relatively simple and enables the estimation of predictive distributions with accuracy. Models were specified by (i) the log-likelihood function Eq. 6) making use of the "zero-trick" approach (Ntzoufras, 2009), (ii) the logit functions (Eqs. 7, 8 or (9) depending on the type of regression model, and (iii) the distribution of priors. In fitting each model, two MCMC simulations were run for 30000 iterations each with two sets of potential initial values for the model parameters. Once the chains were tested for convergence to equilibrium, the Deviance Information Criterion (DIC) was obtained. Posterior means, standard deviations, $95 \%$ credible intervals and Monte Carlo (MC) errors were obtained for the model parameters allowing for a burn-in period of 4000 iterations (i.e., statistics computed with the results from iteration \#4001 until \#30 000). The suitability of a model against another as inferred by their DIC values has been explained in Gonzales-Barron and Butler (2011a). In relation to the prior distributions used, most model parameters had non-informative priors. Uniform distributions or beta $(1,1)$ were used as priors of the zero-inflated probability $w_{o}$ (Model 1 ) and the binomial probability $p$ (Model 2). In the case of the standard deviation $\sigma_{u}$ of the random effects (Models 3 and 4), the non-informative prior used for the precision $(1 /$ variance) was a gamma $(0.01,0.01)$ so that the precision would be very low, and therefore the standard deviation very high (high uncertainty). The priors used for the fixed effects $\beta_{k}$ (Model 1) and $\gamma_{k}$ (Models 2, 3 and 4) were normal distributions with mean zero and a low precision of 0.001 . In this way, the posterior distributions for the model parameters were then set to be driven basically by the log-likelihood function (Eq. 6). Additionally, estimates of mean prevalence for each sampling site and overall mean prevalence at any site were directly computed from the MCMC script for every pathogen.

\subsection{Performance of sampling plans}

Once output distributions had been characterised, cumulative distributions were computed in MS Excel. Then, the probability of detecting a positive sample was calculated for each pathogen based on the mean prevalence estimated by the model showing the best fit to data observed. The number of samples (n) to reject batches at specified probabilities (p) was estimated at each microbial limit, following the methodology stated by Whiting et al. (2006). For a two-class attributes sampling plan with sample size $\mathrm{n}$ and different values of $\mathrm{c}$ (maximum permitted number of samples exceeding the microbial limit, being in this case set to 0 ), the probability of rejection (r) followed a binomial distribution and was calculated as follows:

$r=1-(1-p)^{n}$

Rearranging this formula, the required number of samples would be: $n \geq \frac{\log (1-r)}{\log (1-p)}$

\section{Results and discussion}

The data sets of the three pathogens had in common a high proportion of non-detections $(s=0)$. A summary of the observed individual sampling results per pathogen and product type is shown in Table 1. The individual prevalence was lower for Salmonella spp. (1.20\%) comparing to that obtained for Listeria $(2.34 \%)$ and S. aureus (2.11\%). Observed results at batch level are represented in Fig. 1. Salmonella spp. was the pathogen least frequently detected in poultry meat ( $90.9 \%$ non-detections at batch level), while L. monocytogenes and $S$. aureus were not detected in $85-86 \%$ of the batches; although in general the frequency of non-detections were conditional upon the sampling site. The histograms of the observed incidence, drawn based on the probability estimate $\widehat{p}_{i}=s_{i} / n_{i}$ from every sampling visit or batch $i$, suggested that the statistical representation of these prevalence data,

Table 1

Summary of the observed individual sampling results (number of positives (s) and total number of samples (n)) per each product type and pathogen tested.

\begin{tabular}{llll}
\hline Sampling site & \multicolumn{3}{l}{ Pathogen } \\
\cline { 2 - 4 } & Salmonella & L. monocytogenes & S. aureus \\
\hline Carcass & $s=2 ; n=255$ & $s=7 ; n=255$ & $\mathrm{~s}=5 ; n=245$ \\
Wings & $s=6 ; n=256$ & $s=2 ; n=252$ & $s=8 ; n=239$ \\
Thigh & $s=7 ; n=505$ & $s=17 ; n=505$ & $s=12 ; n=490$ \\
Breast & $s=1 ; n=314$ & $s=5 ; n=314$ & $s=2 ; n=303$ \\
Total & $s=16 ; n=1330$ & $s=31 ; n=1326$ & $s=27 ; n=1277$
\end{tabular}


and any inferential statistics thereof, ought to be based on a more flexible approach than the basic logit model (i.e., binomial distribution), so that the high proportion of non-detections could be accounted for Fig. 1.

\subsection{Adequacy of zero-inflated binomial (ZIB) regression models}

As a strategy to account for the high proportion of non-detections, two zero-inflated processes were initially contemplated: the zero-inflated binomial (ZIB, with two parameters as shown in the previous Section) and the zero-inflated beta-binomial (ZIBB, with an additional parameter characterising the degree of variability in the "unknown" binomial probability). When fitted to the data without any covariates or random-effects, the ZIB distribution was not different, in terms of fitting performance, from the ZIBB distribution for describing the occurrence of Salmonella (DIC 102.6 for ZIB and 103.2 for ZIBB), L. monocytogenes (DIC 162.0 for ZIB and 161.8 for ZIBB) and S. aureus (DIC 149.8 for ZIB and 150.4 for ZIBB; results not shown). For this reason, the regression models testing the effect of sampling site on microbial prevalence were all based on the simpler ZIB distribution.

To illustrate the difference between the standard binomial and the ZIB distribution - the underlying distribution of the regression models presented in this work, consider a ZIB process of known parameters $\omega_{0}=0.8$ and $p=0.25$. Suppose that from every batch, ten samples are withdrawn $(n=10)$, and that the total sampled batches are 100 . The expected histogram of frequencies of the number of positive samples $\mathrm{s}$ from such ZIB process is shown in Fig. 2. The mean proportion of positive samples from the ZIB process would be $\left(1-\omega_{0}\right) \times p=0.05$. That is, the probability that a sample taken from that process be positive for a given pathogen is 0.05 . If we described such a process using a standard binomial distribution with $p=0.05$, it will become obvious that the binomial renders a poor fit despite both distributions having the same expected value (Fig. 2). Thus, the underlying parameter $\mathrm{p}$ that represents the contaminated fraction in a ZIB distribution can accurately describe the "true" occurrence of the pathogen, which can find numerous applications in risk assessments and sampling plans' design.

Consistently, for the three data sets, the sampling site was found to exert greater effect on the extra proportion of non-detections $w_{0}$ (Model 2 ) than on the binomial prevalence $p$ (Model 1). Notice that having the same number of parameters, Model 2 yielded lower DIC values than Model 1 for Salmonella (89.4 as opposed to 104.5; Table 2), L. monocytogenes (159.0 as opposed to 163.7; Table 3 ) and $S$. aureus (136.1 as opposed to 151.3; Table 4). According to Model 1, the extra proportion of non-detections $w_{0}$, which cannot be accounted for by the binomial process, was high at 55.4\% (95\% CI: $7.8-84.4 \%$ ) for Salmonella, $57.8 \%$ (95\% CI: $22.7-76.8 \%$ ) for L. monocytogenes and $53.2 \%$ for $S$. aureus (95\% CI: $13.9-76.2 \%$ ). The broad confidence intervals shown above implied that $w_{0}$ presented a high variability likely to originate from the

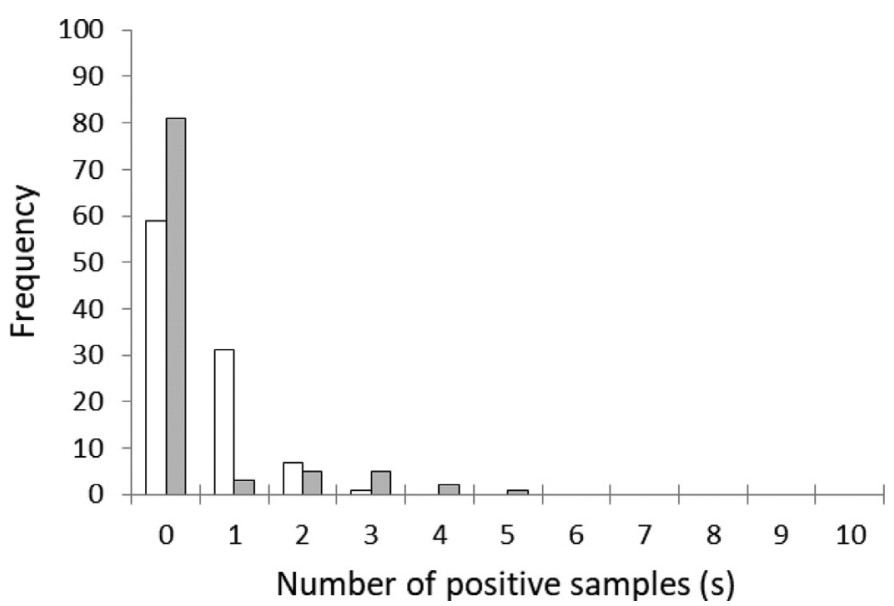

different sampling sites. Thus, some sampling sites would be more contamination-free than others. In fact, Model 2 was capable of depicting such differences when the fixed effects of sampling site were placed on $w_{0}$. For this reason, Model 2 became the basis model for testing the significance of random effects due to sampling occasion (Models 3 and 4).

With an additional parameter - standard deviation of the random effects located either in the extra proportion of zeros $\left(w_{0}\right)$ or in the binomial probability $(p)$, the random-effects models 3 and 4 were fitted. Although for the three microorganisms, the addition of random-effects did not improve the DIC values, the better capacity of the random-effects models to describe the pathogens' occurrence data was deduced from the lower deviances of Models 3 and 4 in comparison to those of the simpler Model 2, particularly when modelling the occurrence of $L$. monocytogenes (deviances 140.6 and 143.4 as opposed to 156.7; Table 3) and S. aureus (deviances 140.2 and 141.9 as opposed to 146.7; Table 4). Both random-effects models evidenced the significant effect of sampling site on the extra proportion of non-detections. Analysis of the values of $\gamma_{1}, \gamma_{2}, \gamma_{3}$ and $\gamma_{4}$ fitted by Models 3 and 4 suggests that the extra proportion of non-detections followed, for the three pathogens, the decreasing order breast $>$ carcass $>$ thigh (numerically, not always statistically significant), which ultimately produced mean prevalence values following the increasing order breast $<$ carcass $<$ thigh. For both Salmonella spp. (Table 2) and $S$. aureus (Table 4), wings produced the lowest extra proportion of non-detections, significantly different from the other sites. Accordingly, higher mean prevalence values were found on wings for Salmonella $(0.0161 ; 0.0144)$ and S. aureus $(0.0347$; 0.0243) when fitting Models 3 and 4, respectively. In the case of $L$. monocytogenes (Table 3 ), carcass $\left(\gamma_{1}\right)$ and thighs $\left(\gamma_{4}\right)$ produced the lowest proportions of extra non-detections - not statistically differing one from another; hence yielding the highest mean prevalence values according to Model 3 (0.0327 and 0.0315, respectively) and Model 4 ( 0.0243 and 0.0226 , respectively). While it is true that, in practical terms, "non-contaminated 25-g units" may not provide sufficient confidence about the "contamination-free" status of the larger sample they represent (carcass, thigh, wings or breast), still the fact that Model 2 described the observed incidence data better than Model 1 consistently for the three pathogens, may suggest that "clean patches" occur more frequently in some chicken parts (breast, carcass) than others (wings, thigh), which probably arises from contamination patterns during processing and handling. These results are consistent for L. monocytogenes with those reported by Schäfer et al. (2017) where higher prevalence levels were detected in thigh than in breast chicken samples. Nevertheless, this assumption can be tested in the future by increasing the representativeness of the sample, either by taking more 25-g units from the same chicken or by using surface swabbing methods.

In terms of fitting performance, for the three pathogens, Model 3 consistently produced lower deviance and DIC values than Model 4

Fig. 2. Expected histogram of frequencies of the number of contaminated samples (s) out of a total of 10 sample units, taken from 100 production batches, whose microbial contamination is assumed to follow a zero-inflated binomial process $\left(\omega_{0}=0.8 ; p=0.4\right.$; in grey bars). A binomial probability function with the same expected mean value is shown for comparison (in white bars). 
Table 2

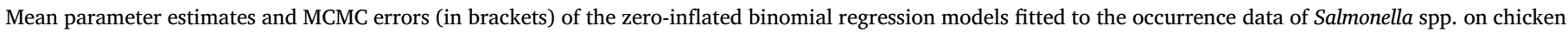
meat. Additional estimates of mean prevalence and 95\% CI are also shown.

\begin{tabular}{|c|c|c|c|c|}
\hline No. parameters & $\begin{array}{l}\text { Model } 1 \\
6\end{array}$ & $\begin{array}{l}\text { Model } 2 \\
6\end{array}$ & $\begin{array}{l}\text { Model } 3 \\
7\end{array}$ & $\begin{array}{l}\text { Model } 4 \\
7\end{array}$ \\
\hline \multicolumn{5}{|l|}{ Fixed effects } \\
\hline Intercept $\left(\beta_{0}\right)$ & $\begin{array}{l}-3.795 \\
(0.120)\end{array}$ & $\begin{array}{r}-3.845 \\
(0.027)\end{array}$ & $\begin{array}{r}-4.079 \\
(0.015)\end{array}$ & $\begin{array}{r}-4.275 \\
(0.020)\end{array}$ \\
\hline Carcass $\left(\beta_{1}\right)$ & $\begin{array}{l}-0.318^{\mathrm{b}} \\
(0.109)\end{array}$ & - & - & - \\
\hline Wings $\left(\beta_{2}\right)$ & $\begin{array}{l}0.911^{\mathrm{d}} \\
(0.114)\end{array}$ & - & - & - \\
\hline Breast $\left(\beta_{3}\right)$ & $\begin{array}{l}-1.296^{\mathrm{a}} \\
(0.102)\end{array}$ & - & - & - \\
\hline Thigh $\left(\beta_{4}\right)$ & $\begin{array}{l}0.405^{\mathrm{c}} \\
(0.114)\end{array}$ & - & - & - \\
\hline Intercept $\left(\gamma_{0}\right)$ & $\begin{array}{l}0.189 \\
(0.022)\end{array}$ & $\begin{array}{c}-3.951 \\
(0.225)\end{array}$ & $\begin{array}{r}-5.965 \\
(0.208)\end{array}$ & $\begin{array}{r}-6.427 \\
(0.182)\end{array}$ \\
\hline Carcass $\left(\gamma_{1}\right)$ & - & $\begin{array}{l}-0.079^{\mathrm{b}} \\
(0.055)\end{array}$ & $\begin{array}{l}-0.043^{\mathrm{b}} \\
(0.046)\end{array}$ & $\begin{array}{l}-0.041^{\mathrm{b}} \\
(0.040)\end{array}$ \\
\hline Wings $\left(\gamma_{2}\right)$ & - & $\begin{array}{l}-1.249^{\mathrm{a}} \\
(0.063)\end{array}$ & $\begin{array}{l}-1.984^{\mathrm{a}} \\
(0.043)\end{array}$ & $\begin{array}{l}-1.879^{\mathrm{a}} \\
(0.044)\end{array}$ \\
\hline Breast $\left(\gamma_{3}\right)$ & - & $\begin{array}{l}1.122^{\mathrm{c}} \\
(0.059)\end{array}$ & $\begin{array}{l}2.086^{c} \\
(0.049)\end{array}$ & $\begin{array}{l}1.715^{\mathrm{c}} \\
(0.047)\end{array}$ \\
\hline Thigh $\left(\gamma_{4}\right)$ & - & $\begin{array}{l}-0.389^{b} \\
(0.057)\end{array}$ & $\begin{array}{l}-0.700^{\mathrm{b}} \\
(0.047)\end{array}$ & $\begin{array}{l}-0.527^{\mathrm{b}} \\
(0.039)\end{array}$ \\
\hline \multicolumn{5}{|l|}{ Random effects } \\
\hline$\sigma_{\mathrm{u}}$ due to season & - & - & $\begin{array}{l}3.228 \\
(0.275)\end{array}$ & $\begin{array}{l}0.656 \\
(0.010)\end{array}$ \\
\hline \multicolumn{5}{|l|}{ Goodness-of-fit } \\
\hline Mean deviance & 102.1 & 102.6 & 101.6 & 102.7 \\
\hline DIC & 104.5 & 89.4 & 96.6 & 103.1 \\
\hline \multicolumn{5}{|l|}{ Additional estimates } \\
\hline Mean $w_{0}$ & $\begin{array}{l}0.5540 \\
(0.0780-0.8340)\end{array}$ & - & - & - \\
\hline Mean binomial $p$ & - & $\begin{array}{l}0.0256 \\
(0.0085-0.0817)\end{array}$ & $\begin{array}{l}0.0192 \\
(0.0082-0.0555)\end{array}$ & $\begin{array}{l}0.0163 \\
(0.0046-0.0486)\end{array}$ \\
\hline Mean prev. carcass & $\begin{array}{l}0.0085 \\
(0.0010-0.0253)\end{array}$ & $\begin{array}{l}0.0118 \\
(0.022-0.0239)\end{array}$ & $\begin{array}{l}0.0125 \\
(0.0014-0.0245)\end{array}$ & $\begin{array}{l}0.0113 \\
(0.0019-0.0261)\end{array}$ \\
\hline Mean prev. wings & $\begin{array}{l}0.0233 \\
(0.0077-0.0485)\end{array}$ & $\begin{array}{l}0.0176 \\
(0.0078-0.0380)\end{array}$ & $\begin{array}{l}0.0161 \\
(0.0071-0.0339)\end{array}$ & $\begin{array}{l}0.0144 \\
(0.0044-0.0361)\end{array}$ \\
\hline Mean prev. breast & $\begin{array}{l}0.0109 \\
(0.0002-0.0138)\end{array}$ & $\begin{array}{l}0.0081 \\
(0.0005-0.0187)\end{array}$ & $\begin{array}{l}0.0088 \\
(0.0002-0.0195)\end{array}$ & $\begin{array}{l}0.0083 \\
(0.0004-0.0213)\end{array}$ \\
\hline Mean prev. thigh & $\begin{array}{l}0.0143 \\
(0.0052-0.0292)\end{array}$ & $\begin{array}{l}0.0135 \\
(0.0057-0.0246)\end{array}$ & $\begin{array}{l}0.0137 \\
(0.0016-0.0274)\end{array}$ & $\begin{array}{l}0.0122 \\
(0.0037-0.0261)\end{array}$ \\
\hline Mean prev. any site* & $\begin{array}{l}0.0253 \\
(0.0003-0.1592)\end{array}$ & $\begin{array}{l}0.0133 \\
(0.0010-0.0333)\end{array}$ & $\begin{array}{l}0.0135 \\
(0.0015-0.0270)\end{array}$ & $\begin{array}{l}0.0123 \\
(0.0022-0.0298)\end{array}$ \\
\hline
\end{tabular}

a,b,c,d Different superscript letters denote statistical differences in intercept shifts between sampling sites.

*Computed from the intercepts $\beta_{0}$ and $\gamma_{0}$ without considering the effect of sampling site.

while extracting a greater amount of variability due to sampling occasion (as implied by the considerably higher estimates of $\sigma_{u}$ in Tables 2, 3 and 4). Despite the fact that the variability in $w_{0}$ had been accounted for by the sampling site, there still remained significant residual variability in $w_{0}$ to accommodate the random effects due to sampling occasion or batch $\left(\sigma_{u}=3.23\right.$ for Salmonella, $\sigma_{u}=6.51$ for $L$. monocytogenes and $\sigma_{u}=4.95$ for $S$. aureus). In other words, under a zero-inflated binomial assumption, most of the between-batch variability in the occurrence of pathogens lay in the process producing the extra proportion of non-detections (i.e., zones with absence of contamination) than in the binomial probability itself. In fact, the addition of a random-effects term to the binomial probability extracting between-batch variability did not considerably improve Model 3 (results not shown).

Apart from the goodness-of-fit criteria, to further compare the performance of Models 3 and 4, the prevalence observations $\widehat{p}_{i}$ were averaged by sampling site for each of the three pathogens and compared to their respective mean prevalence values estimated from Model 3 and 4 (Tables 2-4). Fig. 3 shows that the estimates from Model 3 approximated better to the observed mean prevalence values than those from Model 4. In most cases, Model 4 produced lower mean prevalence estimates than Model 3, while for higher mean prevalence levels (prevalence $\sim 0.04$ ), Model 4 underestimated the observed mean prevalence values to a greater extent than Model 3. It is probable that the zero-inflated binomial assumption no longer holds as non-detections become less frequent (i.e., lower proportion of extra non-detections). When contamination levels are higher, and hence binomial probabilities become more variable, more complex models such as the zeroinflated beta-binomial may be more suitable.

Among all models tested, the zero-inflated binomial model with random-effects in the extra proportion of non-detections (Model 3) provided a good representation of the occurrence of the three pathogens on chicken meat. With such a model, the mean prevalence at any sampled site (breast, carcass, thigh or wings) was estimated as 0.0135 (95\% CI: 0.0015 - 0.0270) for Salmonella, 0.0211 (95\% CI: $0.0004-$ $0.0563)$ for L. monocytogenes and 0.0236 (95\% CI: $0.0004-0.0512)$ for $S$. aureus. Significantly higher prevalence levels were reported by the EFSA Zoonoses Report; for Salmonella (6.45\%) and by Akbar and Anal (2013) and Thapaliya et al. (2017) for multidrug resistant $S$. aureus strains in poultry meat. Differences in prevalence with other studies can be attributed to the number of samples collected in our study and deviations in the analytical methodologies used for pathogen detection in comparison with other works which can yield underestimated prevalence levels (Reiter et al., 2007). Other related factors 
Table 3

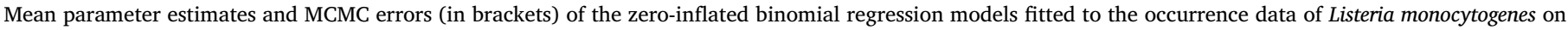
chicken meat. Additional estimates of mean prevalence and 95\% CI are also shown.

\begin{tabular}{|c|c|c|c|c|}
\hline No. parameters & $\begin{array}{l}\text { Model } 1 \\
6\end{array}$ & $\begin{array}{l}\text { Model } 2 \\
6\end{array}$ & $\begin{array}{l}\text { Model } 3 \\
7\end{array}$ & $\begin{array}{l}\text { Model } 4 \\
7\end{array}$ \\
\hline \multicolumn{5}{|l|}{ Fixed effects } \\
\hline Intercept $\left(\beta_{0}\right)$ & $\begin{array}{r}-2.930 \\
(0.096)\end{array}$ & $\begin{array}{r}-2.666 \\
(0.017)\end{array}$ & $\begin{array}{r}-2.923 \\
(0.016)\end{array}$ & $\begin{array}{l}-3.511 \\
(0.031)\end{array}$ \\
\hline Carcass $\left(\beta_{1}\right)$ & $\begin{array}{l}0.179^{c} \\
(0.095)\end{array}$ & - & - & - \\
\hline Wings $\left(\beta_{2}\right)$ & $\begin{array}{l}-1.055^{\mathrm{a}} \\
(0.090)\end{array}$ & - & - & - \\
\hline Breast $\left(\beta_{3}\right)$ & $\begin{array}{l}-0.277^{\mathrm{b}} \\
(0.093)\end{array}$ & - & - & - \\
\hline Thigh $\left(\beta_{4}\right)$ & $\begin{array}{l}0.532^{\mathrm{d}} \\
(0.096)\end{array}$ & - & - & - \\
\hline Intercept $\left(\gamma_{0}\right)$ & $\begin{array}{l}0.324 \\
(0.008)\end{array}$ & $\begin{array}{l}0.261 \\
(0.239)\end{array}$ & $\begin{array}{c}-0.033 \\
(0.200)\end{array}$ & $\begin{array}{c}-1.272 \\
(0.196)\end{array}$ \\
\hline Carcass $\left(\gamma_{1}\right)$ & - & $\begin{array}{l}-1.332^{\mathrm{a}} \\
(0.085)\end{array}$ & $\begin{array}{l}-1.787^{\mathrm{a}} \\
(0.083)\end{array}$ & $\begin{array}{l}-1.834^{\mathrm{a}} \\
(0.075)\end{array}$ \\
\hline Wings $\left(\gamma_{2}\right)$ & - & $\begin{array}{l}1.822^{\mathrm{c}} \\
(0.082)\end{array}$ & $\begin{array}{l}2.580^{c} \\
(0.082)\end{array}$ & $\begin{array}{l}2.169^{c} \\
(0.088)\end{array}$ \\
\hline Breast $\left(\gamma_{3}\right)$ & - & $\begin{array}{l}0.177^{\mathrm{b}} \\
(0.081)\end{array}$ & $\begin{array}{l}0.404^{\mathrm{b}} \\
(0.078)\end{array}$ & $\begin{array}{l}0.230^{\mathrm{b}} \\
(0.082)\end{array}$ \\
\hline Thigh $\left(\gamma_{4}\right)$ & - & $\begin{array}{l}-0.845^{\mathrm{a}} \\
(0.082)\end{array}$ & $\begin{array}{l}-1.546^{\mathrm{a}} \\
(0.093)\end{array}$ & $\begin{array}{l}-1.425^{\mathrm{a}} \\
(0.072)\end{array}$ \\
\hline \multicolumn{5}{|l|}{ Random effects } \\
\hline$\sigma_{\mathrm{u}}$ due to batch & - & - & $\begin{array}{l}6.508 \\
(0.608)\end{array}$ & $\begin{array}{l}0.904 \\
(0.022)\end{array}$ \\
\hline \multicolumn{5}{|l|}{ Goodness-of-fit } \\
\hline Mean deviance & 158.8 & 156.7 & 140.6 & 143.4 \\
\hline DIC & 163.7 & 159.0 & 158.5 & 158.6 \\
\hline \multicolumn{5}{|l|}{ Additional estimates } \\
\hline Mean $w_{O}$ & $\begin{array}{l}0.5781 \\
(0.2778-0.7679)\end{array}$ & - & - & - \\
\hline Mean binomial $p$ & - & $\begin{array}{l}0.0700 \\
(0.0253-0.0684)\end{array}$ & $\begin{array}{l}0.0539 \\
(0.0248-0.0984)\end{array}$ & $\begin{array}{l}0.0336 \\
(0.0104-0.0870)\end{array}$ \\
\hline Mean prev. carcass & $\begin{array}{l}0.0263 \\
(0.0098-0.0523)\end{array}$ & $\begin{array}{l}0.0357 \\
(0.0162-0.0615)\end{array}$ & $\begin{array}{l}0.0327 \\
(0.0029-0.0621)\end{array}$ & $\begin{array}{l}0.0243 \\
(0.0087-0.0481)\end{array}$ \\
\hline Mean prev. wings & $\begin{array}{l}0.0097 \\
(0.0013-0.0280)\end{array}$ & $\begin{array}{l}0.0069 \\
(0.0004-0.0246)\end{array}$ & $\begin{array}{l}0.0079 \\
(0.0001-0.0421)\end{array}$ & $\begin{array}{l}0.0063 \\
(0.0003-0.0216)\end{array}$ \\
\hline Mean prev. breast & $\begin{array}{l}0.0176 \\
(0.0054-0.0394)\end{array}$ & $\begin{array}{l}0.0184 \\
(0.0053-0.0374)\end{array}$ & $\begin{array}{l}0.0171 \\
(0.0002-0.0478)\end{array}$ & $\begin{array}{l}0.0144 \\
(0.0036-0.0303)\end{array}$ \\
\hline Mean prev. thigh & $\begin{array}{l}0.0351 \\
(0.0181-0.0595)\end{array}$ & $\begin{array}{l}0.0316 \\
(0.0162-0.0524)\end{array}$ & $\begin{array}{l}0.0315 \\
(0.0031-0.0581)\end{array}$ & $\begin{array}{l}0.0226 \\
(0.0088-0.0424)\end{array}$ \\
\hline Mean prev. any site* & $\begin{array}{l}0.0413 \\
(0.0011-0.1981)\end{array}$ & $\begin{array}{l}0.0235 \\
(0.0014-0.0690)\end{array}$ & $\begin{array}{l}0.0211 \\
(0.0004-0.0563)\end{array}$ & $\begin{array}{l}0.0165 \\
(0.0010-0.0426)\end{array}$ \\
\hline
\end{tabular}

a,b,c,d Different superscript letters denote statistical differences in intercept shifts between sampling sites.

*Computed from the intercepts $\beta_{0}$ and $\gamma_{0}$ without considering the effect of sampling site.

such as the slaughterhouse capacity, hygienic conditions during dressing, evisceration and chilling can influence on pathogens' transmission through the poultry chain (Reich et al., 2018).

\subsection{Performance of sampling plans}

The ZIB approach provides a binomial parameter $\mathrm{p}$ (probability of a positive result among the contaminated fraction) that can be readily used in the design of sampling plans. Taking the example presented above (Fig. 2), under a standard binomial assumption, the required number of samples to fail with a probability of 0.95 , and an overall prevalence of 0.05 would be 58 (Eq. 12). Yet, if we were only interested in failing batches with contamination, the parameter $p(0.25)$ from the ZIB distribution should be instead used in Eq. 12. By doing so, only 10 samples would be needed.

Performance of sampling plans was first assessed by using the mean prevalence values from the model showing the best representation of the data (Model 3: ZIB model with random-effects in the extra proportion of non-detections). If a target probability of acceptance is set at 0.05 (95\% probability of rejecting the batch), wings were the sampling site where higher probability of detection was obtained for both Salmonella spp. ( $n=185$ samples) and $S$. aureus $(n=85$ samples $)$. In contrast, for L. monocytogenes, thigh was the sampling site showing higher probability of detection ( $n=94$ samples for rejecting the batch at $95 \%$ confidence). The obtained number of samples was calculated from the estimated prevalence values for wings given by Model 3 in Tables $2-4$. When considering the binomial $\mathrm{p}$ values calculated from the ZIB models for the different pathogens, a substantial reduction in the number of samples tested would be achieved in comparison to the estimated prevalence per sampling site. For Salmonella, Listeria and Staphylococcus spp., the number of samples needed using the ZIB model to reject poultry batches at $95 \%$ certainty (regardless of sampling site) were 155,55 , and 71 respectively. For those sampling sites showing a higher proportion of non-detects, even greater savings would be expected by using Model 3 assumption. For instance, the estimated Salmonella spp. prevalence for breast is 0.0088 from Model 3 (Table 2). Thus, to reject batches at $95 \%$ certainty, the required number of samples would be $n=339$, while assuming the binomial $\mathrm{p}$ value for any product the number of samples would still be $n=155$. This clearly shows the usefulness of the ZIB model in the improvement of sampling plan performance, considering that microbial contamination present in any part of the chicken carcass would lead to batch rejection (or at least a hygiene warning). It should be noted that sampling plans could serve here as a verification tool since lower number of samples implies higher 
Table 4

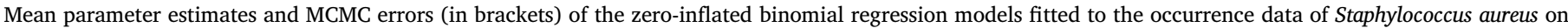
chicken meat. Additional estimates of mean prevalence and 95\% CI are also shown.

\begin{tabular}{|c|c|c|c|c|}
\hline No. parameters & $\begin{array}{l}\text { Model } 1 \\
6\end{array}$ & $\begin{array}{l}\text { Model } 2 \\
6\end{array}$ & $\begin{array}{l}\text { Model } 3 \\
7\end{array}$ & $\begin{array}{l}\text { Model } 4 \\
7\end{array}$ \\
\hline \multicolumn{5}{|l|}{ Fixed effects } \\
\hline Intercept $\left(\beta_{0}\right)$ & $\begin{array}{r}-3.030 \\
(0.128)\end{array}$ & $\begin{array}{r}-3.208 \\
(0.021)\end{array}$ & $\begin{array}{c}-3.187 \\
(0.377)\end{array}$ & $\begin{array}{r}-3.834 \\
(0.038)\end{array}$ \\
\hline Carcass $\left(\beta_{1}\right)$ & $\begin{array}{l}-0.027^{\mathrm{b}} \\
(0.124)\end{array}$ & - & - & - \\
\hline Wings $\left(\beta_{2}\right)$ & $\begin{array}{c}0.413^{\mathrm{b}} \\
(0.125)\end{array}$ & - & - & - \\
\hline Breast $\left(\beta_{3}\right)$ & $\begin{array}{l}-1.324^{\mathrm{a}} \\
(0.119)\end{array}$ & - & - & - \\
\hline Thigh $\left(\beta_{4}\right)$ & $\begin{array}{l}0.213^{\mathrm{b}} \\
(0.125)\end{array}$ & - & - & - \\
\hline Intercept $\left(\gamma_{0}\right)$ & $\begin{array}{l}0.111 \\
(0.013)\end{array}$ & $\begin{array}{c}-2.471 \\
(0.200)\end{array}$ & $\begin{array}{c}-1.661 \\
(0.197)\end{array}$ & $\begin{array}{r}-5.383 \\
(0.186)\end{array}$ \\
\hline Carcass $\left(\gamma_{1}\right)$ & - & $\begin{array}{l}-0.185^{b} \\
(0.046)\end{array}$ & $\begin{array}{l}0.599^{\mathrm{b}} \\
(0.054)\end{array}$ & $\begin{array}{l}-0.269^{b} \\
(0.045)\end{array}$ \\
\hline Wings $\left(\gamma_{2}\right)$ & - & $\begin{array}{l}-1.777^{\mathrm{a}} \\
(0.053)\end{array}$ & $\begin{array}{l}-2.820^{\mathrm{a}} \\
(0.050)\end{array}$ & $\begin{array}{l}-1.347^{\mathrm{a}} \\
(0.060)\end{array}$ \\
\hline Breast $\left(\gamma_{3}\right)$ & - & $\begin{array}{l}1.533^{\mathrm{c}} \\
(0.062)\end{array}$ & $\begin{array}{l}1.409^{c} \\
(0.049)\end{array}$ & $\begin{array}{l}1.365^{\mathrm{c}} \\
(0.059)\end{array}$ \\
\hline Thigh $\left(\gamma_{4}\right)$ & - & $\begin{array}{l}0.017^{\mathrm{b}} \\
(0.056)\end{array}$ & $\begin{array}{l}0.489^{b} \\
(0.056)\end{array}$ & $\begin{array}{l}-0.195^{\mathrm{b}} \\
(0.049)\end{array}$ \\
\hline \multicolumn{5}{|l|}{ Random effects } \\
\hline$\sigma_{\mathrm{u}}$ due to season & - & - & $\begin{array}{l}4.952 \\
(0.262)\end{array}$ & $\begin{array}{l}1.103 \\
(0.023)\end{array}$ \\
\hline \multicolumn{5}{|l|}{ Goodness-of-fit } \\
\hline Mean deviance & 146.5 & 146.7 & 140.2 & 141.9 \\
\hline DIC & 151.3 & 136.1 & 137.0 & 141.9 \\
\hline \multicolumn{5}{|l|}{ Additional estimates } \\
\hline Mean $w_{O}$ & $\begin{array}{l}0.5325 \\
(0.1395-0.7620)\end{array}$ & - & - & - \\
\hline Mean binomial $p$ & - & $\begin{array}{l}0.0419 \\
(0.0173-0.0908)\end{array}$ & $\begin{array}{l}0.0418 \\
(0.0205-0.0825)\end{array}$ & $\begin{array}{l}0.0263 \\
(0.0045-0.0768)\end{array}$ \\
\hline Mean prev. carcass & $\begin{array}{l}0.0222 \\
(0.0067-0.0487)\end{array}$ & $\begin{array}{l}0.0222 \\
(0.0072-0.0412)\end{array}$ & $\begin{array}{l}0.0201 \\
(0.0001-0.0447)\end{array}$ & $\begin{array}{l}0.0206 \\
(0.0033-0.0608)\end{array}$ \\
\hline Mean prev. wings & $\begin{array}{l}0.0322 \\
(0.0131-0.0620)\end{array}$ & $\begin{array}{l}0.0332 \\
(0.0164-0.0604)\end{array}$ & $\begin{array}{l}0.0347 \\
(0.0091-0.0622)\end{array}$ & $\begin{array}{l}0.0243 \\
(0.0042-0.0718)\end{array}$ \\
\hline Mean prev. breast & $\begin{array}{l}0.0073 \\
(0.0010-0.0209)\end{array}$ & $\begin{array}{l}0.0124 \\
(0.0017-0.0280)\end{array}$ & $\begin{array}{l}0.0148 \\
(0.0001-0.0400)\end{array}$ & $\begin{array}{l}0.0144 \\
(0.0012-0.0484)\end{array}$ \\
\hline Mean prev. thigh & $\begin{array}{l}0.0263 \\
(0.0123-0.0473)\end{array}$ & $\begin{array}{l}0.0221 \\
(0.0098-0.0370)\end{array}$ & $\begin{array}{l}0.0211 \\
(0.0004-0.0443)\end{array}$ & $\begin{array}{l}0.0205 \\
(0.0036-0.0607)\end{array}$ \\
\hline Mean prev. any site & $\begin{array}{l}0.0493 \\
(0.0006-0.2357)\end{array}$ & $\begin{array}{l}0.0231 \\
(0.0016-0.0520)\end{array}$ & $\begin{array}{l}0.0236 \\
(0.0004-0.0512)\end{array}$ & $\begin{array}{l}0.0211 \\
(0.0026-0.0641)\end{array}$ \\
\hline
\end{tabular}

a,b,c,d Different superscript letters denote statistical differences in intercept shifts between sampling sites.

*Computed from the intercepts $\beta_{0}$ and $\gamma_{0}$ without considering the effect of sampling site.

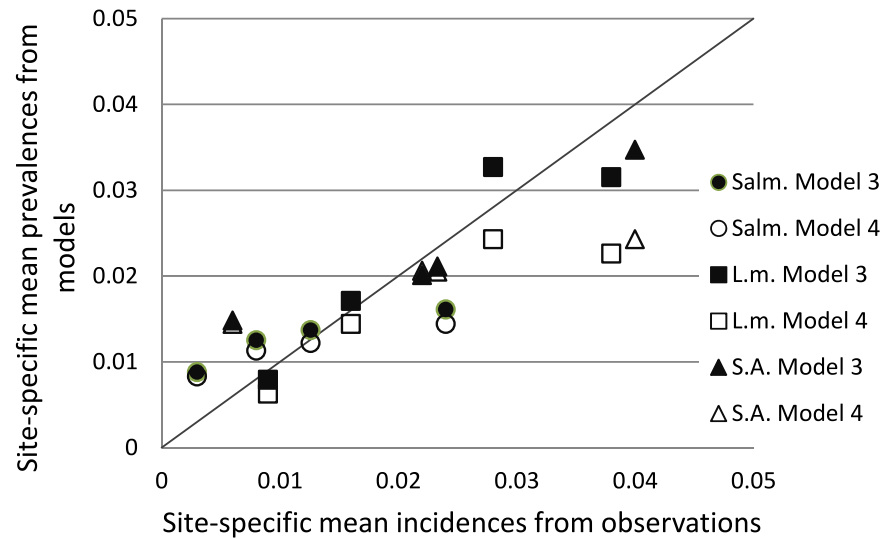

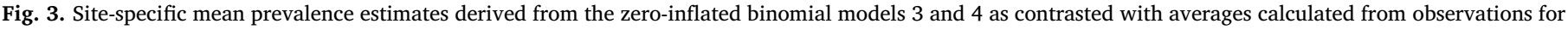
the occurrence data sets for Salmonella spp. (Salm), L. monocytogenes (L.m.) and S. aureus (S.A) on chicken meat. 
uncertainty in rejecting a batch.

The outcomes of the ZIB models can be readily used by food industries to improve sampling plans performance in order to increase the rejection rate of non-compliant batches. The generated models can be further implemented in an Excel spreadsheet and/or sampling software so that microbial limits for defining a unit as defective or acceptable can be set by risk managers to allow for proper decision-making and to be able to identify need for improvement. In the above explained example, the ZIB models yielded a lower number of samples to reject non-compliant batches which can be well considered by food authorities when setting national sampling surveillance programs in those food products where a low microbial prevalence is expected.

\section{Conclusion}

The zero-inflated binomial (ZIB) assumption was appropriate to describe low microbial prevalence data ( $<4 \%$ mean prevalence), such as those of Salmonella, L. monocytogenes and $S$. aureus in poultry meat; and, furthermore, the assumption provided the basis for performing inferential statistics by means of a ZIB regression. A random-effects ZIB regression allowed the estimation of mean prevalence levels by sampling site (i.e., carcass, wings, thighs and breast) within a single model. In addition, under a ZIB assumption, it was found that most of the between-batch variability in the occurrence of the three pathogens on chicken meat lies in the process producing the extra proportion of nondetections (viz. zones with absence of contamination) than in the binomial probability itself. With basis on an adequate description of microbial contamination, sampling procedures of poultry meat can be effectively addressed. Thus, performance of sampling plans represents a potential application of the generated models for food safety assurance. It was shown that the probability of detecting a positive sample of Salmonella spp, and $S$. aureus is higher by collecting wings samples, however, for L. monocytogenes thigh yielded more contaminated samples so that the probability of detecting a positive was higher. These findings highlight the importance of zero inflated binomial models for describing low microbial prevalence and for designing microbial sampling plans.

\section{Acknowledgments}

Dr. Gonzales-Barron wishes to acknowledge the financial support provided by the Portuguese Foundation for Science and Technology (FCT) through the award of a five-year Investigator Fellowship (IF) in the mode of Development Grants (IF/00570).

\section{Supplementary materials}

Supplementary material associated with this article can be found, in the online version, at doi:10.1016/j.mran.2018.07.002.

\section{References}

Akbar, A., Kumar Anal, A., 2013. Prevalence and antibiogram study of Salmonella and Staphylococcus aureus in poultry meat. Asian Pac. J. Trop. Biomed. 3 (2), 163-168. https://doi.org/10.1016/S2221-1691(13)60043-X.

Alonso-Hernando, A., Prieto, M., García-Fernández, C., Alonso-Calleja, C., Capita, R. 2012. Increase over time in the prevalence of multiple antibiotic resistance among isolates of Listeria monocytogenes from poultry in Spain. Food Control 23, 37-41. https://doi.org/10.1016/j.foodcont.2011.06.006.
Carpentier, B., Cerf, O., 2011. Review-Persistence of Listeria monocytogenes in food industry equipment and premises. Int. J. Food Microbiol 145, 1-8. https://doi.org/10 1016/j.ijfoodmicro.2011.01.005.

Dookeran, M.M., Baccus-Taylor, G.S., Akingbala, J.O., Tameru, B., Lammerding, A.M., 2012. Transmission of Salmonella on broiler chickens and carcasses from production to retail in Trinidad and Tobago. J. Agr. Biodiv. Res. 1, 78-84.

EFSA (European Food Safety Authority) and ECDC (European Centre for Disease Prevention and Control), 2017. The European Union summary report on trends and sources of zoonoses, zoonotic agents and food-borne outbreaks in 2016. EFSA J. 2017 15 (12), 5077, 228. doi:10.2903/j.efsa.2017.5077.

Elmali, M., Can, H.Y., Yaman, H., 2015. Prevalence of Listeria monocytogenes in poultry meat. Food Sci. Technol 35 (4), 672-675. https://doi.org/10.1590/1678-457X.6808.

Farrell, D., 2013. The Role of Poultry in Human nutrition. Poultry development Review. Food and Agriculture Organization of the United Nations, pp. 2-3.

Gonzales-Barron, U., Butler, F., 2011a. A comparison between the discrete PoissonGamma and Poisson-Lognormal distributions to characterise microbial counts in foods. Food Control 22, 1279-1286. https://doi.org/10.1016/j.foodcont.2011.01. 029.

Gonzales-Barron, U., Butler, F., 2011b. Characterisation of within-batch and betweenbatch variability in microbial counts in foods using Poisson-gamma and Poissonlognormal regression models. Food Control 22, 1268-1278. https://doi.org/10. 1016/j.foodcont.2011.01.028.

Gonzales-Barron, U., Cadavez, V., Butler, F., 2014. Conducting inferential statistics for low microbial counts in foods using the Poisson-gamma regression. Food Control 37 385-394. https://doi.org/10.1016/j.foodcont.2013.09.032.

International Organization for Standarization (ISO), 1999. ISO microbiology of food and animal feeding stuffs - horizontal method for the enumeration of coagulase-positive Staphylococci (Staphylococcus aureus and other species) - Part 2: technique using rabbit plasma fibrinogen agar medium. ISO 6888-2, 1999.

International Organization for Standarization (ISO), 2002. ISO microbiology of food and animal feeding stuffs - horizontal method for the detection of Salmonella spp. ISO 6579, 2002.

International Organization for Standarization (ISO), 2004. ISO microbiology of food and animal feeding stuffs - horizontal method for the detection and enumeration of Listeria monocytogenes - Part 2: enumeration method. ISO 11290-2:1998/Amd1:2004.

International Organization for Standarization (ISO), 2017. ISO microbiology of food and animal feeding stuffs - horizontal method for the detection and enumeration of Listeria monocytogenes - Part 1: detection method. ISO 11290-1:1996/Amd1:2017.

Ntzoufras, I., 2009. Bayesian Modeling using WinBUGS, first ed. John Wiley \& Sons, New Jersey ISBN: 978-0-470-14114-4.

Oniciuc, E.A., Nicolau, A.I., Hernández, M., Rodríguez-Lázaro, D., 2017. Presence of methicillin-resistant Staphylococcus aureus in the food chain. Trends Food Sci. Technol 61, 49-59. https://doi.org/10.1016/j.tifs.2016.12.002.

Pasquali, F., De Cesare, A., Meunier, M., Guyard, M., Rivoal, K., Chemaly, M., Manfreda, G., 2017. Poultry quality evaluation. Quality Attributes and Consumer Values 159-195. https://doi.org/10.1016/B978-0-08-100763-1.00007-6. A volume in Woodhead Publishing Series in Food Science, Technology and Nutrition. Chapter 7: Current challenges in poultry meat safety.

Reich, F., Valero, A., Schill, F., Bungenstock, L., Klein, G., 2018. Characterisation of Campylobacter contamination in broilers and assessment of microbiological criteria for the pathogen in broiler slaughterhouses. Food Control 87, 60-69. https://doi.org/ 10.1016/j.foodcont.2017.12.013.

Reiter, M.G.R., Fiorese, M.L., Moretto, G., López, M.C., Jordano, R., 2007. Prevalence of Salmonella in a poultry slaughterhouse. J. Food Prot. 70 (7), 1723-1725. https://doi. org $/ 10.4315 / 0362-028 X-70.7 .1723$.

Sahu, S.S., Kim, B., Ferguson, M.S., Zink, D.L., Datta, A.R., 2017. Growth potential of Listeria monocytogenes in artificially contaminated celery and chicken salad. Food Control 73, 1229-1236. https://doi.org/10.1016/j.foodcont.2016.10.044.

Schäfer, D.F., Steffens, J., Barbosa, J., Zeni, J., Paroul, N., Valduga, E., Junges, A., Backes, G.T., Cansian, R.L., 2017. Monitoring of contamination sources of Listeria monocytogenes in a poultry slaughterhouse. LWT Food Sci. Technol 86, 393-398. https:// doi.org/10.1016/j.lwt.2017.08.024.

Thapaliya, D., Forshey, B.M., Kadariya, J., Quick, M.K., Farina, S., O'Brien, A., Nair, R., Nworie, A., Hanson, B., Kates, A., Wardyn, S., Smith, T.C., 2017. Prevalence and molecular characterization of Staphylococcus aureus in commercially available meat over a one-year period in Iowa, USA. Food Microbiol 65, 122-129. https://doi.org/ 10.1016/j.fm.2017.01.015.

Wang, H., Wang, H., Liang, L., Xu, X., Zhou, G., 2018. Prevalence, genetic characterization and biofilm formation in vitro of Staphylococcus aureus isolated from raw chicken meat at retail level in Nanjing. China. Food Control 86, 11-18. https://doi.org/10. 1016/j.foodcont.2017.10.028.

Whiting, R.C., Rainosek, A., Buchanan, R.L., Miliotis, M., LaBarre, D., Long, W., Ruple, A., Schaub, S., 2006. Determining the microbiological criteria for lot rejection from the performance objective or food safety objective. Int. J. Food Microbiol. 110 (3), 263-267. https://doi.org/10.1016/j.ijfoodmicro.2006.04.038. 